\title{
Aplastic anemia during pregnancy: a review of obstetric and anesthetic considerations
}

This article was published in the following Dove Press journal:

International Journal of Women's Health

\section{Efrain Riveros-Perez' \\ Amy C Hermesch ${ }^{2}$ \\ Linda A Barbour ${ }^{3}$ \\ Joy L Hawkins ${ }^{4}$}

'Department of Anesthesiology and Perioperative Medicine, Medical

College of Georgia, Augusta University, Augusta, GA, ${ }^{2}$ Maternal

Fetal Medicine, ${ }^{3}$ Obstetrics and Gynecology, ${ }^{4}$ Department of Anesthesiology, University of Colorado School of Medicine, Aurora, CO, USA
Correspondence: Efrain Riveros-Perez Department of Anesthesiology and Perioperative Medicine, Medical College of Georgia, Augusta University, I I 20 I5th Street, Augusta, GA 30912, USA Tel +l 706721736 I

Email eriverosperez@augusta.edu

\begin{abstract}
Aplastic anemia is a hematologic condition occasionally presenting during pregnancy. This pathological process is associated with significant maternal and neonatal morbidity and mortality. Obstetric and anesthetic management is challenging, and treatment requires a coordinated effort by an interdisciplinary team, in order to provide safe care to these patients. In this review, we describe the current state of the literature as it applies to the complexity of aplastic anemia in pregnancy, focusing on pathophysiologic aspects of the disease in pregnancy, as well as relevant obstetric and anesthetic considerations necessary to treat this challenging problem. A multidisciplinary-team approach to the management of aplastic anemia in pregnancy is necessary to coordinate prenatal care, optimize maternofetal outcomes, and plan peripartum interventions. Conservative transfusion management is critical to prevent alloimmunization. Although a safe threshold-platelet count for neuraxial anesthesia has not been established, selection of anesthetic technique must be evaluated on a case-to-case basis.
\end{abstract}

Keywords: aplastic anemia, platelets, high-risk obstetrics, obstetric anesthesia, pregnancy

\section{Background}

Aplastic anemia (AA) is a life-threatening disorder ${ }^{1}$ that tends to worsen during pregnancy. This disorder consists of pancytopenia as a result of hypocellular bone marrow in the absence of an abnormal infiltrate or bone-marrow fibrosis., ${ }^{2,3}$ The diagnosis of AA during pregnancy is associated with significant fetal, neonatal, and maternal morbidity and mortality. ${ }^{4}$ Growth restriction affects the fetus, and neonatal sepsis is more prevalent among babies from mothers with AA. ${ }^{5}$ A causal relationship between pregnancy and AA has not been conclusively established; ${ }^{6}$ however, women with AA can become pregnant, since there is no compromise of fertility. In these cases, obstetric and neonatal complications range between $12 \%$ and $33 \%{ }^{7,8}$ Furthermore, in the presence of thrombocytopenia, hemorrhagic complications during the peripartum period requiring blood transfusions have been reported to have incidence as high as $75 \% .{ }^{9}$ Anesthetic, hematologic, and obstetric care during pregnancy is discussed in this paper from an interdisciplinary standpoint. Therapy during the peripartum period is also approached in the context of a review of recent literature.

\section{Review of literature}

Acquired AA is an uncommon disorder characterized by progressive pancytopenia caused by altered bone-marrow function. Incidence is estimated to be one to two cases per million per year. ${ }^{10}$ Given the complexity of AA and the limited experience by most providers, new guidelines by the British Society for Standards in Haematology on the diagnosis and management of adult AA were recently published. ${ }^{3}$ Pathogenic 
mechanisms underlying this disease are likely to be immunomediated, and include the overproduction of bone-marrowinhibiting cytokines elicited by abnormal T-cell response in a genetically predisposed individual. ${ }^{11}$ Pregnancy in association with $\mathrm{AA}$ is a rare but serious condition that poses serious maternal and fetal risks. Unfortunately, most of the current literature has been limited to case reports, with few studies exploring risk factors and perinatal complications. ${ }^{12,13}$

\section{Pathophysiology of aplastic anemia}

Acquired AA is more common than the hereditary form. Typically, this disorder affects young adults who present with peripheral pancytopenia in the absence of other hematological diseases. ${ }^{14}$ Classification of AA determines indication for treatment, and depends on etiology and severity (Table 1 ). ${ }^{2} \mathrm{AA}$ in the adult can be idiopathic ( $>80 \%$ of cases) or induced by pharmacologic agents, infections (particularly hepatitis), or hereditary forms with late-onset manifestations (eg, related to telomeropathies). Therapy is indicated in symptomatic disease, severe and very severe cases, and patients classified as nonsevere in whom severe cytopenia of at least one cell line requiring transfusions is present.

Although the hematologic stem-cell (HSC) compartment is affected in all types of AA, in the acquired form, the damage is extrinsic and involves direct and indirect mechanisms. Direct injury can be caused by radiation therapy and cytotoxic agents, whereas indirect damage involves immunoeffector pathways, which are responsible for idiopathic cases and present in those preceded by a history of hepatitis. ${ }^{15,16}$ Crossreactive marrow antigen recognition by $T$ cells is postulated as the causative mechanism in most idiopathic cases of the disease (Figure 1). ${ }^{17}$ Evidence supporting the role of the immune system in HSC injury includes serologic and cytokine data and the dramatic clinical response to therapy with immunomodulatory agents in animals. ${ }^{18-20}$

The HSC/progenitor cell is the target of immune attack by activated T cells. The antigens responsible for autoimmunization remain elusive; however, autoantibodies have been identified in serum of patients with AA. ${ }^{21}$ The association between human leukocyte antigens (HLAs) and susceptibility to develop AA has been widely studied. Nakao et al isolated a

Table I Classification of aplastic anemia based on severity

\begin{tabular}{llll}
\hline Cells & Nonsevere* & Severe & Very severe \\
\hline Neutrophils & $<\mathrm{I} \times 10^{9} \mathrm{cells} / \mathrm{L}$ & $<0.5 \times 10^{9} \mathrm{cells} / \mathrm{L}$ & $<0.2 \times 10^{9} \mathrm{cells} / \mathrm{L}$ \\
Platelets & $<50 \times 10^{9} \mathrm{cells} / \mathrm{L}$ & $<20 \times 10^{9} \mathrm{cells} / \mathrm{L}$ & $<20 \times 10^{9} \mathrm{cells} / \mathrm{L}$ \\
Reticulocytes & $<20 \times 10^{9} \mathrm{cells} / \mathrm{L}$ & $<20 \times 10^{9} \mathrm{cells} / \mathrm{L}$ & $<20 \times 10^{9} \mathrm{cells} / \mathrm{L}$ \\
\hline
\end{tabular}

Note: *In addition to $<25 \%$ bone marrow cellularity. population of $\mathrm{CD}^{+} \mathrm{T}$ cells able to target hematopoietic cells positive for HLA-DRB1*0405, supporting the hypothesis that certain HLA alleles may play a role in activation of T-cell clones in $\mathrm{AA} .{ }^{22}$ On the other hand, it has been postulated that certain HLA alleles might confer protection against autoreactive T-cell activation. ${ }^{23}$

In addition to individual susceptibility, T-cell dysregulation is necessary for AA to develop. Transcriptional analysis has shown altered regulation of $\mathrm{CD}^{+}$and $\mathrm{CD}^{+} \mathrm{T}$ cells, whereas abnormal expansion of $\mathrm{T}$-helper $\left(\mathrm{T}_{\mathrm{H}}\right)-1, \mathrm{~T}_{\mathrm{H}} 2$, and $\mathrm{T}_{\mathrm{H}} 17$ cell populations and underexpression of the $\mathrm{T}_{\text {reg }}$ immunophenotype occur consistently in AA. ${ }^{24,25}$ Autoreactive T-cells produce proinflammatory cytokines, including TNF $\alpha$ and IFN $\gamma{ }^{26,27}$ Both cytokines induce apoptosis, reducing colony formation of hematopoietic progenitor cells. ${ }^{28}$ Furthermore, intracellular expression of these cytokines predicts response to immunotherapy and is associated with poor clinical outcome. ${ }^{29,30}$ Aside from abnormal cellular immunity, other factors have been implicated in the pathogenesis of AA, including the role of innate immunity via depressed NK cells ${ }^{31}$ and mutations in telomerase-complex genes that lead to decreased proliferation and survival of hematopoietic progenitor cells. ${ }^{32-34}$

Paroxysmal nocturnal hemoglobinuria (PNH) has been considered a late clonal disease occurring in patients recovering from AA, and sometimes these two disorders overlap. ${ }^{35}$ As is the case with AA, PNH is linked to HLA antigens, and immunosuppressive therapy is useful to control the disease. Complement inhibitors, such as the monoclonal antibody eculizumab, have proven useful for treatment of $\mathrm{PNH}$, highlighting the underlying mechanism of red-blood-cell destruction and bone-marrow suppression. This therapy has been used with success in pregnancy. ${ }^{36}$

\section{Pathophysiology in pregnancy}

The first report of AA was published by Ehrlich in 1888 . Incidentally, his patient was pregnant and died 1 month after delivery, due to postpartum hemorrhage. ${ }^{37}$ The causal relationship between pregnancy and AA is still unclear. ${ }^{38}$ Earlier studies found no correlation between the conditions, and a retrospective study comparing the frequency of pregnancy in 35 newly diagnosed patients with the expected frequency in the general population found no significant difference. ${ }^{38,39}$ Other reports endorse a direct association between pregnancy and $\mathrm{AA},{ }^{40}$ and pregnancy is even included as a cause of AA in some reviews. ${ }^{41}$

Hemorrhage and sepsis are the major reasons for death in pregnant women with AA. ${ }^{9}$ When AA is present before 


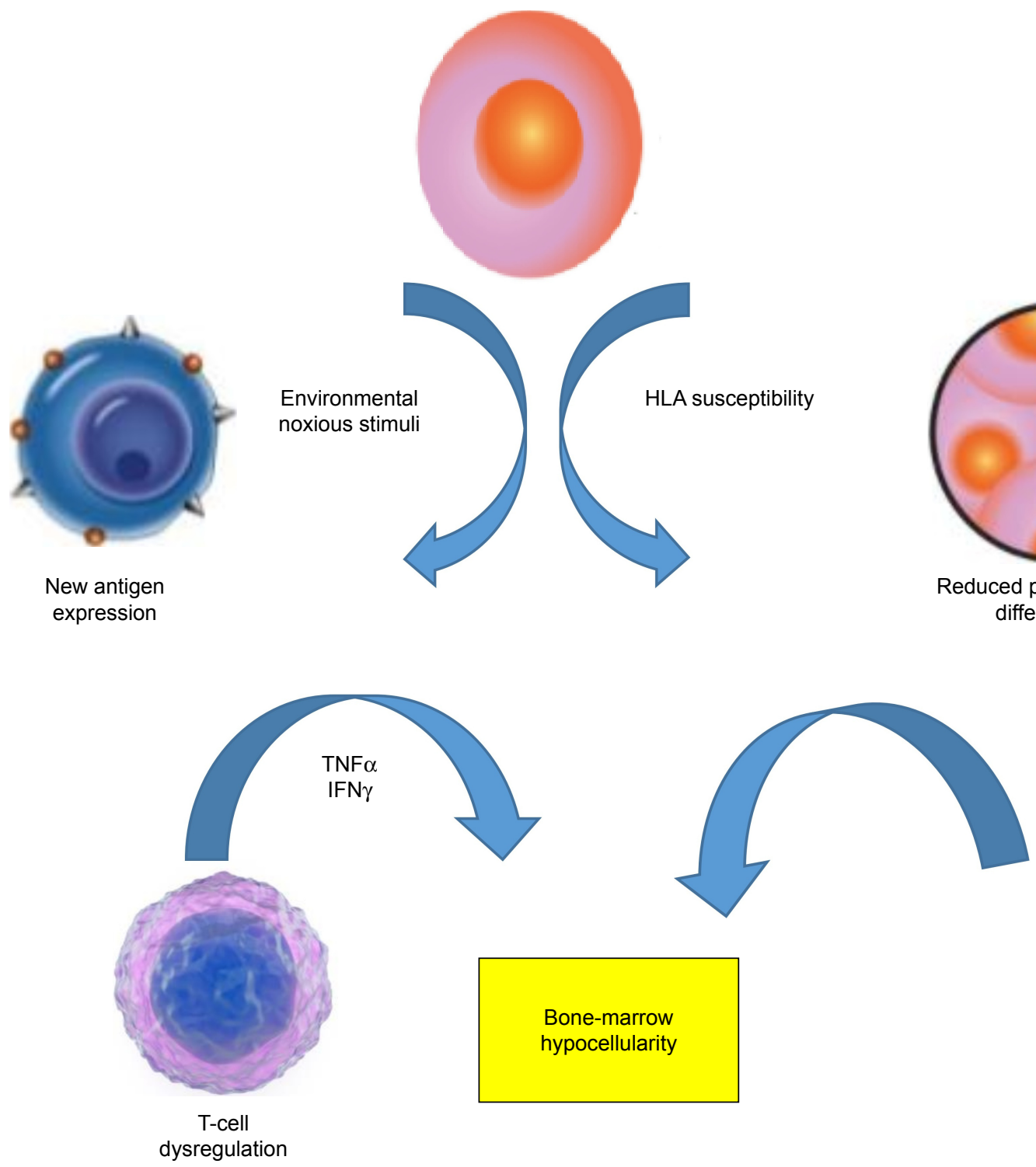

Figure I Pathophysiologic mechanisms of aplastic anemia. Abbreviation: HLA, human leukocyte antigen.

conception, it usually worsens during pregnancy, ${ }^{42}$ and most series have reported a significant decrease in platelet count in almost all women with AA preceding pregnancy. ${ }^{9,43}$ Some authors have reported remission of AA after delivery, and others have suggested that termination of pregnancy should be considered for AA in pregnancy, especially in those patients with severe disease. ${ }^{44}$

Pathophysiological mechanisms underlying the association between AA and pregnancy have not been clearly elucidated. It is known that estrogens increase plasma volume in pregnancy more than red-blood-cell production, resulting in anemia of pregnancy. It has been postulated that hormonal influences may contribute to worsening of blood counts in pregnant patients with $\mathrm{AA}$, but the exact mechanism and causes are still unclear. ${ }^{45,46}$ Animal models have provided some insight into mechanisms for altered maturation and proliferation of blood cells in pregnancy. In a murine model, Zoller et al showed that injection of $17 \beta$-estradiol inhibits the development of developing thymocytes. ${ }^{47}$ Zhdanov et al demonstrated enhanced proliferative activity of erythroid precursors in bone marrow that was increased by concomitant administration of iron. ${ }^{48}$ According to one theory, a population of primitive $\mathrm{CD} 34^{+}$progenitors responsible for cellular proliferation and regeneration is produced in maternal bone marrow in response to interaction with umbilical cord blood cells via immunologic signals. ${ }^{49}$ Pregnancy is also sometimes accompanied by gestational thrombocytopenia and relative leukocytosis. The factors responsible for the observed 
thrombocytopenia in pregnant patients with AA are yet to be definitively elucidated..$^{50}$

\section{Maternal and fetal considerations in aplastic anemia in pregnancy Treatment of aplastic anemia in pregnancy} Principles of AA treatment during pregnancy include identification of any underlying cause and treatment of cytopenias, while minimizing maternal and fetal side effects of therapy. Termination should be considered if a triggering factor causing bone-marrow suppression, such as drug reaction or infection, is detected, and the medication cannot be discontinued or the microorganism cannot be adequately treated if pregnancy continues. Waiting for spontaneous resolution without further treatment is not recommended, as it places the patient at risk of complications related to pancytopenia. ${ }^{51}$ Pregnancy termination should also be considered for patients with severe pancytopenia, given the high likelihood of life-threatening maternal and fetal complications. Furthermore, in a recent series of 61 women with AA, those with more severe thrombocytopenia had a sixfold-higher complication rate related to one of the composite pregnancy outcomes - preeclampsia/eclampsia, preterm delivery, intrauterine growth restriction, and fetal and neonatal death - and an elevenfold increase in the composite outcomes, which included transfusion dependence after delivery, sepsis, and bone-marrow transplant. ${ }^{9}$

The most common complications of AA in pregnancy, in addition to postpartum hemorrhage, include premature rupture of membranes, endometritis, growth restriction, subchorionic hematoma, and placental abruption. Management of AA starts with accurate diagnosis, definition of severity, and a comprehensive assessment, followed by supportive treatment. Some therapies recommended for AA in the nonobstetric population include hematopoietic stem-cell transplantation (HSCT) and use of immunosuppressive regimens. ${ }^{52}$ HSCT, albeit associated with significant 5-year survival rates in nonpregnant patients, ${ }^{53}$ is contraindicated in pregnancy, due to teratogenicity associated with pretransplant immunosuppressant agents. ${ }^{54}$ Termination of pregnancy in order to perform HSCT is not usually recommended, because of the relatively favorable prognosis for mother and fetus when medical therapy is optimally used. ${ }^{55}$ HSCT can be performed in the postpartum period. Immunosuppressant agents are excreted in breast milk, and some practitioners do not recommend breastfeeding while on those medications in the context of HSCT; however, reports of successful immunosuppression in breastfed infants are encouraging, and the informed decision to recommend breastfeeding must be individualized. ${ }^{56}$ Additionally, reduced fertility is a common clinical manifestation after HSCT, due to gonadal damage secondary to myeloablative conditioning. Fertility prospects must be discussed with the patient before making the decision to proceed with HSCT in the postpartum period..$^{57}$

The optimal treatment for AA depends on different factors, including patient age, neutrophil count, and presence of comorbid conditions. In the nonobstetric population, mild cases can be either observed or treated with specific colony-stimulating factors, antithymocyte globulin (ATG), cyclosporine, and methylprednisolone..$^{58}$ In pregnancy, supportive management with transfusions to hemoglobin $>8 \mathrm{~g} / \mathrm{dL}$ and platelet count $>20 \times 10^{9} / \mathrm{L}$ is recommended. ${ }^{6}$ Additionally, there are reports of patients successfully treated with prednisolone, cyclosporine, and GCSF. ${ }^{5,59}$ Regarding the use of ATG in pregnancy, there is little published experience. A retrospective analysis of a group of 26 patients, including two pregnant women, reported an overall response rate to treatment of $46 \%$ and $45 \%$ survival at 2 years, without special mention of outcome of pregnancy ${ }^{60}$ Aitchison et al reported a case series of five pregnant patients with AA treated with ATG. In his series, four patients were treated during the postpartum period and only one before delivery, receiving the medication at 23 weeks. The baby was delivered at 36 weeks, weighing $1,700 \mathrm{~g}$. The patient died 2 months postpartum as a result of an episode of pneumonia without recovery from her AA. ${ }^{54}$ ATG is a relatively safe medication, with side effects mostly related to allergic reactions, vein irritation, nausea, vomiting, and diarrhea. There are no reports of fetal adverse effects attributable to ATG in humans, and low birth weight might be the result of comorbid conditions, rather than drug toxicity. ${ }^{61}$ Kutzler et al reported the successful use of ATG to treat kidney-transplant rejection in a pregnant patient. ${ }^{61} \mathrm{In}$ an animal study, antithymocyte therapy caused toxic effects, manifested as decreased placental development in a murine model. ${ }^{62}$ There is very limited experience using ATG in pregnancy, and risks and benefits of this therapy are not clear.

If corticosteroids are used, those unable to cross the placenta, such as prednisone, prednisolone, and hydrocortisone, are preferred, in order to minimize fetal brain exposure and the slight association of orofacial malformations. ${ }^{63}$ All corticosteroids may increase the risk of glucose intolerance, gestational diabetes, and premature rupture of membranes, and their benefit is limited in AA compared to immunorelated causes of cytopenias that result from cell destruction (eg, hemolytic anemia and idiopathic thrombocytopenic purpura). Finally, cyclosporine, an immunosuppressant recommended 
for treatment of AA, seems to be associated with premature delivery and low-birth-weight infants, although it is difficult to sort out whether this is due to the medication or an underlying maternal condition. Because cyclosporine has not been shown to be consistently effective, it should be carefully considered by the treating physician. ${ }^{64}$ Although some authors have reported an increase in neutrophil count during pregnancy, ${ }^{65}$ in some instances severe thrombocytopenia can occur. The use of GCSF was shown to be a safe and effective therapy in a retrospective analysis of 38 pregnant patients, and can be recommended when the disorder is accompanied by significant neutropenia. ${ }^{66,67}$

Transfusion of blood products is the mainstay of supportive treatment in AA associated with pregnancy; however, it may lead to complications, including hemochromatosis and (most concerning) HLA alloimmunization. ${ }^{68}$ Alloantibodies against human platelets cause platelet-transfusion refractoriness (PTR). ${ }^{6}$ There are two types of clinically relevant platelet alloantigens: type I antigens are shared with other blood cells and tissue, which include glycoconjugates of the blood-group system and the polymorphic HLA class I molecule; and type II antigens are specific to platelets (human platelet antigens [HPAs]). Alloantibodies to both types of antigens are responsible for PTR. ${ }^{70}$ If PTR is detected in a pregnant patient who has received blood transfusions, then HLA- and/or HPA-compatible platelet transfusions are indicated. ${ }^{71}$

When treating pregnant patients with AA, clinicians encounter significant ethical challenges. Therapy for maternal AA may put the fetus at risk secondary to exposure to medications, whereas maternal complications occurring if AA is left untreated may also affect the developing fetus. The biomedical ethical principles of autonomy, beneficence, nonmaleficence, and justice provide a guideline to make therapeutic decisions in these cases. In general, two rules apply to most ethical dilemmas: the maternal right to autonomy must be granted, and risks, benefits, and alternatives must be presented to the patient for her to make an informed decision. From the legal point of view, it is clear that the rights of the mother prevail over those of the fetus. ${ }^{72}$

\section{Perinatal implications of aplastic anemia}

Pregnancies complicated by AA require a multidisciplinaryteam approach. Collaboration between high-risk obstetricians, hematologists, anesthesiologists, and transfusion-medicine specialists is necessary. Antepartum management includes frequent monitoring for clinically significant depletion of blood cell lines, with the goal of being conservative in terms of transfusion practices. Fetal growth surveillance should be performed by 28 weeks of gestation, and antenatal testing should also be offered by 30-32 weeks, due to the high prevalence of growth restriction.

Mode of delivery should be carefully considered. ${ }^{6}$ Vaginal delivery is preferred, because even with significant thrombocytopenia, hemostasis can typically be achieved with appropriate uterine contraction after delivery. ${ }^{73}$ A platelet count $>20 \times 10^{9} / \mathrm{L}$ is deemed acceptable ${ }^{74}$ for vaginal delivery and $>50 \times 10^{9} / \mathrm{L}$ for cesarean delivery. ${ }^{75}$ Availability of cross-matched blood products can be difficult with a history of previous transfusions and alloimmunization. Multiple transfusions in patients with AA can lead to significant HLA alloimmunization, especially if nonleukocyte reduced blood products have been used. This presents significant problems, given the risk of maternal bleeding at the time of delivery and the potential need for platelets to achieve hemostasis. HLA-matched platelets can be expensive and have limited availability.

Addressing permanent or long-acting reversible contraception is of critical importance, given that AA does not appear to decrease fertility, but is likely to progress or relapse with subsequent pregnancies. Another relevant aspect to consider in the context of AA is the risk of neonatal thrombocytopenia in mothers exposed to platelet transfusions. Neonatal alloimmune thrombocytopenia occurs when maternal antibodies directed against HPAs cross the placenta. Clinically significant neonatal thrombocytopenia associated with HLA alloimmunization has been suggested; ${ }^{76,77}$ however, one prospective study was unable to find this association. $^{78}$

\section{Anesthetic implications of aplastic anemia}

The anesthetic management of a pregnant patient with diagnosis of AA requires coordinated interaction with other care teams, including the blood bank, hematology, obstetrics, interventional radiology, nursing staff, and neonatology. ${ }^{79}$ A comprehensive anesthetic plan should incorporate different aspects, including the presence and degree of cytopenias, infectious and bleeding complications, systemic effects of anemia, and side effects of therapy.

The presence of severe thrombocytopenia, which per se confers poor prognosis in the context of $\mathrm{AA},{ }^{9,80,81}$ puts the patient at risk for surgical bleeding, and may contraindicate the use of neuraxial techniques for labor and delivery. Platelet counts $>50 \times 10^{9} / \mathrm{L}$ are generally considered safe by 
surgeons to perform a cesarean section, ${ }^{73}$ however, there is no absolute number for platelet count unanimously accepted by anesthesiologists to perform a neuraxial block. ${ }^{82}$ The risk of spinal hematoma following epidural and spinal anesthesia is estimated to be $1: 168,000$ and 1:200,000, respectively. ${ }^{83,84}$ In a review of 61 case reports of spinal hematoma after neuraxial anesthesia between 1906 and 1984, Vandermeulen et al found that $68 \%$ of the cases were receiving heparin, and only four cases had thrombocytopenia, with one also being on heparin and another being a chronic alcoholic. This review also suggests that the risks of placing and removing epidural catheters are equivalent. ${ }^{85}$ A retrospective chart review of nonpreeclamptic thrombocytopenia $\left(<100 \times 10^{9} / \mathrm{L}\right)$ reported 47 patients, of whom $91.9 \%$ received regional anesthesia with platelet counts of $80-99 \times 10^{9} / \mathrm{L}$ and $48.1 \%$ with counts of $50-79 \times 10^{9} / \mathrm{L}$, with no neurologic complications. ${ }^{86}$ Another study retrospectively evaluated safety of lumbar puncture in children with acute lymphoblastic leukemia and thrombocytopenia. The authors found that 29 patients with platelet counts $<100 \times 10^{9} / \mathrm{L}, 170$ with counts of $11-20 \times 10^{9} / \mathrm{L}$, and 742 with counts of $21-50 \times 10^{9} / \mathrm{L}$ underwent the procedure with no serious complications. The $95 \%$ CI for serious complications when platelet counts were $20 \times 10^{9} / \mathrm{L}$ or less was $0-1.75 \%$, and was $0-0.37 \%$ when the count was $50 \times 10^{9} / \mathrm{L}$ or less. ${ }^{87}$

Overall, in light of the heterogeneous etiology of thrombocytopenia in retrospective studies and case reports published to date, and recognizing that some patients might have low platelet counts, but normal or even enhanced platelet function, no recommendation regarding a specific threshold of platelet count can be made, and experience of anesthesiologists as well as institutional protocols must be considered to make the decision to perform a neuraxial block in a patient with AA.

The role of the anesthesiologist in management of anemic parturients with AA is critical, and encompasses preoperative assessment, determining need for transfusion, and devising strategies to optimize oxygen consumption:demand ratio. The preoperative assessment must include evaluation of the degree of anemia and determination of signs of cardiovascular compensatory response and compromised organ perfusion. The decision to transfuse should not be based on a "trigger" hemoglobin level, but on evidence of poor organ perfusion, hemodynamic instability despite fluid resuscitation, coexisting diseases, presence of continuing blood loss, and fetal well-being. ${ }^{88}$ Risks of blood transfusions must be balanced against benefits of increasing oxygen delivery in the peripartum setting. ${ }^{89}$ Regarding the use of platelet transfusions prior to epidural analgesia/anesthesia, there is currently no evidence from randomized trials to endorse this practice.

Other aspects related to anesthetic care of AA patients deserve mention, since neuraxial techniques may be contraindicated. The anesthesia-care provider must be ready to use general anesthesia if the patient is to undergo cesarean section. Postoperative pain relief with a multimodal approach is reasonable to facilitate early ambulation and breastfeeding. ${ }^{90}$ Adequate pain management also reduces systemic oxygen consumption, which is critical in the context of anemia. Additionally, inadequate postpartum pain control has been associated with chronic pain and depression..$^{91,92}$ Infection is a risk in AA patients, especially when neutropenia is present. ${ }^{93}$ Precautions must be taken when performing such procedures as venous access, tracheal intubation, and neuraxial blocks. Antibiotic administration before surgical incision is also part of the anesthesiologist's responsibilities. ${ }^{94}$

Systemic analgesia can be obtained with inhaled nitrous oxide and intravenous (IV) opioids. Nitrous oxide administration requires special equipment and patient cooperation. Few good-quality studies have addressed labor analgesia with nitrous oxide, and research on effectiveness, satisfaction, and adverse effects is still needed. ${ }^{95}$ Systemic opioid labor analgesia is widely used around the world; however, the use of narcotics in the obstetric setting has been associated with significant side effects and inferior efficacy when compared with neuraxial techniques. Remifentanil has been used for labor analgesia based on its short context-sensitive half-life. The use of IV patient-controlled analgesia (PCA) with remifentanil has been associated with hypoxic episodes, as well as cardiac and respiratory arrest during labor. ${ }^{96}$ IV PCA remifentanil warrants one-to-one nursing and continuous monitoring of oxygenation, capnography, and patient responsiveness. IV PCA with fentanyl is another alternative for labor analgesia. Miyakoshi et al compared IV PCA fentanyl with no analgesia, showing longer labor in the fentanyl group with no difference in neonatal outcomes and patient satisfaction of $72 \% .{ }^{97}$ Fentanyl is a safe and clinically acceptable analgesic option in labor, especially in nulliparous women. ${ }^{98}$

\section{Conclusion}

AA is a complex disorder that warrants a comprehensive multidisciplinary-team approach, in order to devise an obstetric, hematological, anesthetic, and neonatal plan and anticipate complications during the peripartum period. Conservative transfusion strategies are necessary to avoid complications related to alloimmunization. Close monitoring 
of fetal well-being and adequate growth has to be carried out by the maternofetal specialist, and planning for delivery needs to be discussed, with the vaginal route being the preferred mode. Anesthetic management has to be individualized, and should include considerations related to the degree of blood cell line compromise, as well as possible complications that have an impact on the anesthetic technique. An absolute number of circulating platelet count necessary to perform a safe neuraxial block cannot be recommended at this time, and the choice of the anesthetic technique depends largely on thorough clinical evaluation leading to a judicious balance of risks and benefits on a case-by-case basis. Multimodal labor and postoperative analgesic techniques, including but not limited to the use of systemic opioids, should be considered. Effective contraception is important in light of progression and relapse of AA during pregnancy.

\section{Disclosure}

The authors report no conflicts of interest in this work.

\section{References}

1. Kaufman DW, Kelly JP, Issaragrisil S, et al. Relative incidence of agranulocytosis and aplastic anemia. Am J Hematol. 2006;81(1):65-67.

2. Camitta BM, Storb R, Thomas ED. Aplastic anemia (first of two parts): pathogenesis, diagnosis, treatment, and prognosis. NEngl J Med. 1982; 306(11):645-652.

3. Killick SB, Bown N, Cavenagh J, et al. Guidelines for the diagnosis and management of adult aplastic anaemia. Br J Haematol. 2016;172(2): 187-207.

4. Deka D, Malhotra N, Sinha A, Banerjee N, Kashyap R, Roy KK. Pregnancy associated aplastic anemia: maternal and fetal outcome. J Obstet Gynaecol Res. 2003;29(2):67-72.

5. Ohba T, Yoshimura T, Araki M, et al. Aplastic anemia in pregnancy: treatment with cyclosporine and granulocyte-colony stimulating factor. Acta Obstet Gynecol Scand. 1999;78(5):458-461.

6. Rathore S, Pramanick A, Regi A, Lionel J. Aplastic anemia in pregnancy. J Obstet Gynaecol India. 2014;64 (Suppl 1):26-28.

7. Kwon JY, Lee Y, Shin JC, Lee JW, Rha JG, Kim SP. Supportive management of pregnancy-associated aplastic anemia. Int $J$ Gynaecol Obstet. 2006;95(2):115-120.

8. Li B, Liang MY, Zhang Y, Wand SM, Zhang XH. Aplastic anemia associated with pregnancy: maternal and fetal complications. J Matern Fetal Neonatal Med. 2016;29(7):1120-1124.

9. Shin JE, Lee Y, Kim SJ, Shin JC. Association of severe thrombocytopenia and poor prognosis in pregnancies with aplastic anemia. PLoS One. 2014;9(7):e103066.

10. Montané E, Ibáñez L, Vidal X, et al. Epidemiology of aplastic anemia: a prospective multicenter study. Haematologica. 2008;93(4):518-523.

11. Miano M, Dufour C. The diagnosis and treatment of aplastic anemia: a review. Int J Hematol. 2015;101(6):527-535.

12. Shetty A, Anwar SQ, Acharya S. Aplastic anaemia in pregnancy. J Obstet Gynaecol. 2011;31(1):77-78.

13. Pajor A, Kelemen E, Szakács Z, Lehoczky D. Pregnancy in idiopathic aplastic anemia (report of 10 patients). Eur J Obstet Gynecol Reprod Biol. 1992;45(1):19-25.

14. Risitano AM, Maciejewski JP, Selleri C, Rotoli B. Function and malfunction of hematopoietic stem cells in primary bone marrow failure syndromes. Curr Stem Cell Res Ther. 2007;2(1):39-52.
15. Ohara A, Kojima S, Okamura J, et al. Evolution of myelodysplastic syndrome and acute myelogenous leukaemia in children with hepatitisassociated aplastic anaemia. Br J Haematol. 2002;116(1):151-154.

16. Brown KE, Tisdale J, Barrett AJ, Dunbar CE, Young NS. Hepatitisassociated aplastic anemia. N Engl J Med. 1997;336(15):1059-1064.

17. Baranski B, Armstrong G, Truman JT, Quinnan GV Jr, Straus SE, Young NS. Epstein-Barr virus in the bone marrow of patients with aplastic anemia. Ann Intern Med. 1988;109(9):695-704.

18. Young NS. Current concepts in the pathophysiology and treatment of aplastic anemia. Hematology Am Soc Hematol Educ Program. 2013; 2013:76-81.

19. Scheinberg P, Nunez O, Weinstein B, et al. Horse versus rabbit antithymocyte globulin in acquired aplastic anemia. $N$ Engl J Med. 2011;365(5):430-438

20. Scheinberg P, Nunez O, Young NS. Retreatment with rabbit antithymocyte globulin and ciclosporin for patients with relapsed or refractory severe aplastic anaemia. Br J Haematol. 2006;133(6):622-627.

21. Zeng Y, Katsanis E. The complex pathophysiology of acquired aplastic anaemia. Clin Exp Immunol. 2015;180(3):361-370.

22. Nakao S, Takami A, Takamatsu H, et al. Isolation of a T-cell clone showing HLA-DRB $1 * 0405$-restricted cytotoxicity for hematopoietic cells in a patient with aplastic anemia. Blood. 1997;89(10):3691-3699.

23. Sutton KS, Shereck EB, Nemecek ER, Kurre P. Immune markers of disease severity and treatment response in pediatric acquired aplastic anemia. Pediatr Blood Cancer. 2013;60(3):455-460.

24. Zeng W, Kajigaya S, Chen G, Risitano AM, Nunez O, Young NS. Transcript profile of CD4+ and CD8+ T cells from the bone marrow of acquired aplastic anemia patients. Exp Hematol. 2004;32(9): 806-814.

25. Kordasti S, Marsh J, Al-Khan S, et al. Functional characterization of CD4+ T cells in aplastic anemia. Blood. 2012;119(9):2033-2043.

26. Li J, Zhao Q, Xing W, et al. Interleukin-27 enhances the production of tumour necrosis factor- $\alpha$ and interferon- $\gamma$ by bone marrow $\mathrm{T}$ lymphocytes in aplastic anaemia. Br J Haematol. 2011;153(6):764-772.

27. Wu Q, Zhang J, Shi J, et al. Increased bone marrow (BM) plasma level of soluble CD30 and correlations with BM plasma level of interferon (IFN)- $\gamma, \mathrm{CD} 4 / \mathrm{CD} 8 \mathrm{~T}$-cell ratio and disease severity in aplastic anemia. PLoS One. 2014;9(11):e110787.

28. Lin FC, Karwan M, Saleh B, et al. IFN- $\gamma$ causes aplastic anemia by altering hematopoietic stem/progenitor cell composition and disrupting lineage differentiation. Blood. 2014;124(25):3699-3708.

29. Sloand E, Kim S, Maciejewski JP, Tisdale J, Follmann D, Young NS. Intracellular interferon- $\gamma$ in circulating and marrow $\mathrm{T}$ cells detected by flow cytometry and the response to immunosuppressive therapy in patients with aplastic anemia. Blood. 2002;100(4):1185-1191.

30. Dufour C, Corcione A, Svahn J, Haupt R, Battilana N, Pistoia V. Interferon $\gamma$ and tumour necrosis factor $\alpha$ are overexpressed in bone marrow $\mathrm{T}$ lymphocytes from paediatric patients with aplastic anaemia. Br J Haematol. 2001;115(4):1023-1031.

31. Liu C, Li Z, Sheng W, et al. Abnormalities of quantities and functions of natural killer cells in severe aplastic anemia. Immunol Invest. 2014;43(5):491-503.

32. Brümmendorf TH, Maciejewski JP, Mak J, Young NS, Lansdorp PM. Telomere length in leukocyte subpopulations of patients with aplastic anemia. Blood. 2001;97(4):895-900.

33. Kulasekararaj AG, Jiang J, Smith AE, et al. Somatic mutations identify a subgroup of aplastic anemia patients who progress to myelodysplastic syndrome. Blood. 2014;124(17):2698-2704.

34. Young NS, Bacigalupo A, Marsh JC. Aplastic anemia: pathophysiology and treatment. Biol Blood Marrow Transplant. 2010;16(1 Suppl): S119-S125.

35. Young NS, Maciejewski JP, Sloand E, et al. The relationship of aplastic anemia and PNH. Int J Hematol. 2002;76 Suppl 2:168-172.

36. Sharma R, Keyzner A, Liu J, Bradley T, Allen SL. Successful pregnancy outcome in paroxysmal nocturnal hemoglobinuria (PNH) following escalated eculizumab dosing to control breakthrough hemolysis. Leuk Res Rep. 2015;4(1):36-38. 
37. Ehrlich P. Uber einen Fall von Anämie mit Bemerkungen über regenerative Veränderungen des Knochenmarks. Charite Ann. 1888;13: 300-305.

38. Oosterkamp HM, Brand A, Kluin-Nelemans JC, Vandenbroucke JP. Pregnancy and severe aplastic anaemia: causal relation or coincidence? Br J Haematol. 1998;103(2):315-316.

39. Knispel JW, Lynch VA, Viele BD. Aplastic anemia in pregnancy: a case report, review of the literature, and a re-evaluation of management. Obstet Gynecol Surv. 1976;31(7):523-528.

40. van Besien K, Tricot G, Golichowski A, Padilla L, Hoffman R. Pregnancy-associated aplastic anemia: report of 3 cases. Eur J Haematol. 1991;47(4):253-256.

41. Young NS, Maciejewski J. The pathophysiology of acquired aplastic anemia. N Engl J Med. 1997;336(19):1365-1372.

42. Fleming AF. Hypoplastic anaemia in pregnancy. In: Jepson JH, editor. Clinics in Hematology. Vol 2. London: Saunders; 1973:477-496.

43. Bourantas K, Makrydimas G, Georgiou I, Repousis P, Lolis D. Aplastic anemia: report of a case with recurrent episodes in consecutive pregnancies. J Reprod Med. 1997;42(10):672-674.

44. Cohen E, Ilan Y, Gillis S, Dann EJ, Rachmilewitz EA. Recurrent transient bone marrow hypoplasia associated with pregnancy. Acta Haematol. 1993;89(1):32-34.

45. Brewer CA, Adelson MD, Elder RC. Erythrocytosis associated with a placental-site trophoblastic tumor. Obstet Gynecol. 1992;79(5 Pt 2): 846-849.

46. Jepson JH, Lowenstein L. Role of erythropoietin and placental lactogen in the control of erythropoiesis during pregnancy. Can J Physiol Pharmacol. 1968;46(4):573-576.

47. Zoller AL, Schnell FJ, Kersh GJ. Murine pregnancy leads to reduced proliferation of maternal thymocytes and decreased thymic emigration. Immunology. 2007;121(2):207-215.

48. Zhdanov VV, Udut EV, Sotnikova LS, et al. Pathogenetic evaluation of dysfunction in the erythron system of experimental animals during modeling of iron deficiency anemia in the gestation period. Bull Exp Biol Med. 2016;160(4):417-420.

49. El-Badri NS, Groer M. The effect of pregnancy on production of maternal endogenous hematopoietic stem cells. Biosci Hypotheses. 2008;1(2):100-102.

50. Adam I, Ali AA. Anemia during pregnancy. In: Erkekoğlu P, editor. Nutritional Deficiency. Rijeka, Croatia: InTech; 2016:111-126.

51. Scheinberg P, Young NS. How I treat acquired aplastic anemia. Blood. 2012;120(6):1185-1196.

52. Bacigalupo A. How I treat acquired aplastic anemia. Blood. 2017; 129(11):1428-1436.

53. Young ME, Potter V, Kulasekararaj AG, Mufti GJ, Marsh JC. Haematopoietic stem cell transplantation for acquired aplastic anaemia. Curr Opin Hematol. 2013;20(6):515-520.

54. Aitchison RG, Marsh JC, Hows JM, Russell NH, Gordon-Smith EC. Pregnancy associated aplastic anaemia: a report of five cases and review of current management. Br J Haematol. 1989;73(4):541-545.

55. Stibbe KJ, Wildschut HI, Lugtenburg PJ. Management of aplastic anemia in a woman during pregnancy: a case report. J Med Case Rep. 2011;5:66.

56. Thiagarajan KM, Arakali SR, Mealey KJ, et al. Safety considerations: breastfeeding after transplant. Prog Transplant. 2013;23(2):137-146.

57. Nabhan SK, Bitencourt MA, Duval M, et al. Fertility recovery and pregnancy after allogeneic hematopoietic stem cell transplantation in Fanconi anemia patients. Haematologica. 2010;95(10):1783-1787.

58. Kontomanolis EN, Christoforidou AV, Markopoulou E, et al. Aplastic anaemia and paroxysmal nocturnal haemoglobinuria during pregnancy. J Obstet Gynaecol. 2013;33(4):413-414.

59. Thakral B, Saluja K, Sharma RR, et al. Successful management of pregnancy-associated severe aplastic anemia. Eur J Obstet Gynecol Reprod Biol. 2007;131(2):244-245.

60. Kulkarni S, Sastry PS, Saikia TK, et al. Antilymphocyte globulin (ALG) or antithymocyte globulin (ATG) with methylprednisone and oxymethalone in aplastic anaemia. J Assoc Physicians India. 1997;45(4): 263-266.
61. Kutzler HL, Ye X, Rochon C, Martin ST. Administration of antithymocyte globulin (rabbit) to treat a severe, mixed rejection episode in a pregnant renal transplant recipient. Pharmacotherapy. 2016;36(4):e18-e22.

62. Athanassakis I, Chaouat G, Wegmann TG. The effects of anti-CD4 and anti-CD8 antibody treatment on placental growth and function in allogeneic and syngeneic murine pregnancy. Cell Immunol. 1990; 129(1):13-21.

63. Briggs GG, Freeman RK, Yaffe SJ. Drugs in Pregnancy and Lactation. 8th ed. Philadelphia: Lippincott Williams \& Wilkins; 2008.

64. Paziana K, Del Monaco M, Cardonick E, et al. Ciclosporin use during pregnancy. Drug Saf. 2013;36(5):279-294.

65. Tichelli A, Socié G, Marsh J, et al. Outcome of pregnancy and disease course among women with aplastic anemia treated with immunosuppression. Ann Intern Med. 2002;137(3):164-172.

66. Zeidler C, Grote UA, Nickel A, et al. Outcome and management of pregnancies in severe chronic neutropenia patients by the European branch of the Severe Chronic Neutropenia International Registry. Haematologica. 2014;99(8):1395-1402.

67. Sorbi F, Mecacci F, Di Filippo A, Fambrini M. Pregnancy in Fanconi anaemia with bone marrow failure: a case report and review of the literature. BMC Pregnancy Childbirth. 2017;17(1):53.

68. Ascarelli MH, Emerson ES, Bigelow CL, Martin JN Jr. Aplastic anemia and immune-mediated thrombocytopenia: concurrent complications encountered in the third trimester of pregnancy. Obstet Gynecol. 1998; 91(5 Pt 2):803-806.

69. Rozman P. Platelet antigens: the role of human platelet alloantigens (HPA) in blood transfusion and transplantation. Transpl Immunol. 2002;10(2-3):165-181.

70. Santoso S. Human platelet alloantigens. Transfus Apher Sci. 2003; 28(3):227-236

71. Onishi E, Fujita K, Yokono S. Perioperative management of aplastic anemia in pregnancy with platelet transfusion refractoriness. Can $J$ Anaesth. 2007;54(10):851.

72. State of Illinois vs Mother Doe. In re Baby Boy Doe. 632 NE 2d 326 (1994).

73. Harde M, Dave S, Vasave RR, Gujjar P, Bhadade R. Lower segment cesarean section in a patient with severe thrombocytopenia and pregnancy induced hypertension. J Anaesthesiol Clin Pharmacol. 2013; 29(3):387-389.

74. British Committee for Standards in Haematology, Blood Transfusion Task Force. Guidelines for the use of platelet transfusions. Br J Haematol. 2003;122(1):10-23.

75. Pavithran K, Thomas M. Pregnancy associated aplastic anaemia. J Assoc Physicians India. 1996;44(4):273.

76. Moncharmont P, Dubois V, Obegi C, et al. HLA antibodies and neonatal alloimmune thrombocytopenia. Acta Haematol. 2004;111(4): 215-220.

77. Saito S, Ota M, Komatsu Y, et al. Serologic analysis of three cases of neonatal alloimmune thrombocytopenia associated with HLA antibodies. Transfusion. 2003;43(7):908-917.

78. Thude H, Schorner U, Helfricht C, Loth M, Maak B, Barz D. Neonatal alloimmune thrombocytopenia caused by human leucocyte antigen-B27 antibody. Transfus Med. 2006;16(2):143-149.

79. Moncharmont $\mathrm{P}$, Dubois $\mathrm{V}$, Obegi $\mathrm{C}$, et al. HLA antibodies and neonatal alloimmune thrombocytopenia. Acta Haematol. 2004;111(4):215-220.

80. Hahn JS, Chung KS, Lee SJ, et al. Surgical intervention in patients with aplastic anemia. Yonsei Med J. 1992;33(2):173-182.

81. Kwon JH, Kim I, Lee YG, et al. Clinical course of non-severe aplastic anemia in adults. Int $J$ Hematol. 2010;91(5):770-775.

82. van Veen JJ, Nokes TJ, Makris M. The risk of spinal haematoma following neuraxial anaesthesia or lumbar puncture in thrombocytopenic individuals. Br J Haematol. 2010;148(1):15-25.

83. Ruppen W, Derry S, McQuay H, Moore RA. Incidence of epidural hematoma, infection, and neurologic injury in obstetric patients with epidural analgesia/anesthesia. Anesthesiology. 2006;105(2):394-399.

84. Moen V, Dahlgren N, Irestedt L. Severe neurological complications after central neuraxial blockades in Sweden 1990-1999. Anesthesiology. 2004;101(4):950-959. 
85. Vandermeulen EP, Van Aken H, Vermylen J. Anticoagulants and spinal-epidural anesthesia. Anesth Analg. 1994;79(6):1165-1177.

86. Tanaka M, Balki M, McLeod A, Carvalho JC. Regional anesthesia and non-preeclamptic thrombocytopenia: time to re-think the safe platelet count. Rev Bras Anestesiol. 2009;59(2):142-153.

87. Howard SC, Gajjar A, Ribeiro RC, et al. Safety of lumbar puncture for children with acute lymphoblastic leukemia and thrombocytopenia. JAMA. 2000;284(17):2222-2224.

88. American Society of Anesthesiologists Task Force on Perioperative Blood Management. Practice guidelines for perioperative blood management: an updated report by the American Society of Anesthesiologists Task Force on Perioperative Blood Management. Anesthesiology. 2015;122(2):241-275.

89. Jadon A, Bagai R. Blood transfusion practices in obstetric anaesthesia Indian J Anaesth. 2014;58(5):629-636.

90. Booth JL, Harris LC, Eisenach JC, Pan PH. A randomized controlled trial comparing two multimodal analgesic techniques in patients predicted to have severe pain after cesarean delivery. Anesth Analg. 2016; 122(4):1114-1119.

91. Wisner KL, Stika CS, Clark CT. Double duty: does epidural labor analgesia reduce both pain and postpartum depression? Anesth Analg. 2014;119(2):219-221.
92. Vermelis JM, Wassen MM, Fiddelers AA, Nijhuis JG, Marcus MA. Prevalence and predictors of chronic pain after labor and delivery. Curr Opin Anaesthesiol. 2010;23(3):295-299.

93. Valdez JM, Scheinberg P, Young NS, Walsh TJ. Infections in patients with aplastic anemia. Semin Hematol. 2009;46(3):269-276.

94. Matuschka PR, Cheadle WG, Burke JD, Garrison RN. A new standard of care: administration of preoperative antibiotics in the operating room. Am Surg. 1997;63(6):500-503.

95. Richardson MG, Lopez BM, Baysinger CL, Shotwell MS, Chestnut DH. Nitrous oxide during labor: maternal satisfaction does not depend exclusively on analgesic effectiveness. Anesth Analg. 2017;124(2): $548-553$.

96. Van de Velde M, Carvalho B. Remifentanil for labor analgesia: an evidence-based narrative review. Int J Obstet Anesth. 2016;25: 66-74.

97. Miyakoshi K, Tanaka M, Morisaki H, et al. Perinatal outcomes: intravenous patient-controlled fentanyl versus no analgesia in labor. J Obstet Gynaecol Res. 2013;39(4):783-789.

98. Hosokawa Y, Morisaki H, Nakatsuka I, et al. Retrospective evaluation of intravenous fentanyl patient-controlled analgesia during labor. $J$ Anesth. 2012;26(2):219-224.
International Journal of Women's Health

\section{Publish your work in this journal}

The International Journal of Women's Health is an international, peerreviewed open-access journal publishing original research, reports, editorials, reviews and commentaries on all aspects of women's healthcare including gynecology, obstetrics, and breast cancer. The manuscript management system is completely online and includes

\section{Dovepress}

a very quick and fair peer-review system, which is all easy to use. Visit http://www.dovepress.com/testimonials.php to read real quotes from published authors. 